DOI 10.37882/2223-2982.2021.09-2.22

\title{
МЕТАФОРА ВРЕМЕНИ И ЕЁ ПЕРЕВОД С КИТАЙСКОГО ЯЗЫКА НА РУССКИЙ (ПО МАТЕРИАЛАМ ТЕКСТА КИТАЙСКОЙ ОПЕРЫ КУНЬЦЮЙ «ПИОНОВАЯ БЕСЕДКА»)
}

\section{THE METAPHOR OF TIME AND ITS TRANSLATION FROM CHINESE \\ INTO RUSSIAN (BASED ON THE TEXT \\ OF THE CHINESE OPERA KUN'TSYUY "PEONY GAZEBO")}

Xu Chang

Summary: This article will consider the problem of the national-cultural specificity of the metaphor of time and the options for its translation from Chinese into Russian. The relevance of this research is due to the increased interest in Chinese culture and works of art in connection with the process of globalization and intercultural communication, the demand for studying a variety of complex issues encountered when translating Chinese works into Russian, including the question of translating the metaphor of time. The metaphor of time, as the embodiment of the linguistic picture of the world of a particular ethnic group, has nationalspecific features. It, as a means of actualizing the hidden meanings laid down by the author, and the embodiment of emotionally colored images of the original text, performs the most important task in the text - influencing the imagination of readers. It is precisely with the abovementioned factors that the appearance of numerous works with various versions of its translation is associated. The task of the translator is to find suitable translation methods in order to maximize the transmission of the hidden meaning in the metaphor. To do this, the translator will first need to understand the similarities and differences of the metaphor of time in the two languages, understand the contextual effects used by the original author in this metaphor of time, and accept such suitable translation methods as full translation, transformational translation, free translation and the method of omission.

Keywords: metaphor of time, comparative linguistics, metaphor translation, artistic translation, Kunqu opera.

\author{
Сюй Чан \\ Аспирант, Шанхайский университет \\ иностранных языков \\ zlama@foxmail.com
}

Аннотация: В данной статье будет рассмотрена проблема национальнокультурной специфики метафоры времени и варианты её перевода с китайского языка на русский. Актуальность данного исследования обусловлена возросшим интересом к китайской культуре и произведениям искусства в связи с процессом глобализации и межкультурной коммуникации, востребованностью изучения разнообразных сложных вопросов, встречающихся при переводе китайских произведений на русский язык, в том числе вопрос перевода метафоры времени. Метафора времени, как воплощение языковой картины мира того или иного этноса, обладает национально-специфическими особенностями. Она, как средство актуализации скрытых смыслов, закладываемых автором, и воплощение эмоционально окрашенных образов оригинального текста, выполняет в тексте важнейшую задачу - воздействие на воображение читателей. Именно с вышеупомянутыми факторами связано появление многочисленных трудов с различными вариантами ее перевода. Задача переводчика заключается в нахождении подходящих способов перевода с целью максимальной передачи скрытого смысла в метафоре. Для этого переводчику потребуется для начала разобраться в сходствах и различиях метафоры времени на двух языках, осознать контекстуальные эффекты, используемые первоначальным автором в данной метафоре времени, и принять такие подходящие способы перевода, как полный перевод, трансформационный перевод, вольный перевод и приём опущения.

Ключевые слова: метафора времени, сопоставительная лингвистика, перевод метафоры, художественный перевод, Опера Куньцюй

ностью, сюжетностью, поэтичностью, безусловностью и метафоричностью, что сильно усложняет работу переводчиков. Как заметил Ньюмарк: «Хотя основная проблема перевода - это общий выбор методов перевода текста, наиболее сложным вопросом в работе переводчика является перевод метафор» (Newmark, 1988: 104)

Цель нашего исследования заключается в выявлении особенностей и стратегий перевода метафорического представления тематической группы "времени", опираясь на разъяснении национально-культурных сознательных особенностей в китайском и русском языках. 
Материалом для анализа послужила опера «Пионовая беседка», созданная Тан Сяньцзу, драматургом династии Мин, которая является наиболее представительным образцом оперы Куньцюй и выдающимся культурным и художественным сокровищем китайского народа. 7 сентября 2016 года опера была переведена профессором Ли Иннань на русский язык.

Сюжет оперы: В опере повествуется о Ду Линян, дочери чиновника древнего Китая, которая во сне встречает в пионовом саду возлюбленного, бедного студента по имени Лю Мэнмэй. Не найдя юношу после пробуждения, Ду Линян впадает в тоску, долго болеет и в конце концов умирает. После этого она становится призраком, продолжая искать его по всему свету. Ду Линян рисует картину, в надежде, что однажды юноша найдет её и увидит на ней себя и прекрасную девушку. Лю Мэнмэй сразу же влюбляется. Чудесным образом девушка оживает и влюблённые счастливо живут вместе.

В данной статье были применены следующие методы исследования: метод сопоставления; метод контекстуального и компонентного анализа, метод описания.

Объектом исследования выступают метафоры времени, использованные в текстах оперы Кунзцюй “Пионовая беседка" на китайском и русском языках.

Предметом исследования являются особенности метафоры времени и способы перевода метафоры времени с китайского на русский язык в художественном тексте.

\section{Теоретические основы}

\section{(1) Теория метафоры $\Delta$ K. ^акоффа и М. $\triangle$ консона}

На феномен метафоры обращали внимание такие учёные как Дж. Лакофф [6], Блэк М. [3], Дэвидсон Д. [5], Арутюнова Н.Д. [1], Будаев Э.В. [4], Никитин М.В. [7] и ряд других. Особое место в становлении теории метафоры отводится Дж. Лакоффу и М. Джонсону. Именно они впервые в книге «Метафоры, которыми мы живем» рассматривали феномен метафоры как объект исследования, тщательно и системно описывали его когнитивный механизм, исследовали с точки зрения её связи с глубинными когнитивными структурами и процессов категоризации мира. И с тех времен метафора, как когнитивный феномен, вошла в поле зрения учёных. По мнению Дж. Лакоффа и М. Джонсона, «Метафора пронизывает всю нашу повседневную жизнь и проявляется не только в языке, но и в мышлении и действиях. Наша обыденная понятийная система, в рамках которой мы мыслим и действуем, метафорична по самой своей сути» [6, с.387]. Сами процессы мышления и понятийная система человека в значительной степени метафоричны и в силу это- го, метафоры, как языковые выражения, имеют право на существование. Сущность метафоры состоит в переживании и осмыслении предметов одного рода в терминах сущностей другого рода. Она помогает нам понять чрезвычайно сложные и абстрактные понятия, в том числе и понятие времени, которое принадлежит к определяющим категориям человеческого сознания.

Понятие времени является одним из базисных концептов картины мира и большая часть концептуальной системы посвящена осмыслению времени, где избежать метафорического мышления невозможно. Понятие времени принадлежит к культурным концептам, так как "в каждой культуре существует своя собственная, исконная или заимствованная, система временных понятий" [10, с.2]. В русском и китайском языках также имеется как универсальный, так и специфический национально-культурный способ восприятия и познания абстрактного понятия "Времени” с помощью реальной действительности.

Дж. Лакофф и М. Джонсон выделяют онтологическую метафору, структурную метафору и ориентационную метафору [6]. Опираясь на это, мы также разделяем в данной статье метафору времени на следующие три типа:

1. Онтологическая метафора времени

Это метафора времени, которая базируется на проецировании свойств предметов окружающей действительности, или на индивидуальных человеческих опытах, связанных с физическими объектами, в частности, с человеческим телом, событиями, действиями и т.д. Например: время не ждёт (时间不等人)，时间很长(время длинное) и т.д.

2. Структурная метафора времени

Структурная метафора времени считается структурным метафорическим упорядочиванием абстрактного понятия "время" в терминах другого. Концептуализация понятия "время" осуществляется через уже структурированные, конкретные элементы опыта человека. К такой метафоре относятся следующие: время - деньги (时间就是金钱)；时 间如水 (время - вода) и т.д.

3. Ориентационная метафора времени Ориентационная метафора времени - это метафора, позволяющая познавать понятие "время" с помощью ориентаций в пространстве и направления движения времени. Например: зима ушла (冬 天走了), 年后 (после Праздника весны) и т.д.

\section{(2) Типология способов перевода метафоры}

Проблема перевода метафоры до сих пор остаётся самой обсуждаемой и сложной проблемой в теории перевода. Этот вопрос неоднозначно трактуется такими учёными, как В.Н. Комиссаров [9, с.112], Л.С. Бархударов [2, с.98], Т.А. Казакова [8, с.76] и другие. Эти учёные сходятся во мнении касательно способов, необходимых для 
передачи метафоры. Опираясь на исследованиях этих учёных, мы предлагаем следующие способы перевода метафоры времени: полный перевод, трансформационный перевод, вольный перевод и приём опущения.

Кроме этого, перевод метафоры времени требует, чтобы переводчик, в первую очередь, был хорошо ознакомлен со сходствами и различиями в восприятии и мышлении понятия времени между китайскими и русскими народами, поскольку перевод метафоры времени - это трансформация не только на уровне языка, но и на когнитивно-мыслительном уровне. Самая главная и конечная задача переводчика состоит в том, чтобы передать истинные намерения творчества автора исходного текста на культурном фоне исходного языка, а также способствовать коммуникации мыслительного, познавательного, и эмоционального опыта и культурных ценностей двух народов.

\section{Способы перевода метафоры времени на основе сопоставительного исслеАования китайского и русского языков}

Чтобы более точно и подробно изучить специфику метафоры времени и проблему её перевода с китайского на русский, обратимся к текстам оперы Куньцюй «Пионовая Беседка» на китайском и русском языках. В ходе исследования нами был проведен сопоставительный анализ временных метафор в сознаниях русского и китайского языков, проанализированы способы перевода, авторитетного переводчика Ли Иннань на основе определения и сопоставления временных метафор в русском и китайском текстах.

На основе проведённого исследования возможно выделить всего четыре способа перевода, наиболее подходящие для передачи временных метафор, к ним относятся: полный перевод, трансформационный перевод, описательный перевод и компенсация.

\section{(1) Полный перево}

Полный перевод относится к ситуации, когда переводчик решает в полном объеме сохранить метафорический образ оригинального текста в переведенном тексте. В этом случае, как правило, исходный и целевой языки имеют полное соответствие в способах метафоризации. Например: 梦》)

【隔尾】春啊，得和你两留连，春去如何遣?（《惊

Весна, весна, я так привязалась к тебе!

что буду делать, когда тыууйдёшь?

В представленном примере метафорой является выражение "春去" (весна, когда ты уйдёшь) . Эту метафо- ру можно считать ориентированной. Для её передачи переводчик выбирает полный перевод, так как представление о понятии времени находится в прямой зависимости от представлений человека о пространстве и в обоих языках имеются одинаковые временные метафоры, образующиеся словами, характеризующими пространственные категории.

【前腔】夜长难睡，还向主家借些油去。(《遇母》) Впереди длинная ночь, сразу не заснешь.

Сходите-ка к хозяину, займите масла.

В выбранном примере мы видим онтологическую метафору “夜长”(длинная ночь). Переводчик сохраняет данную метафору в переведённом тексте, поскольку в русском и китайском языках "夜" (ночь) имеет один и тот же способ метафоризации.

\section{【胜如花】也曾落几个黄昏陪待。(《婚走》)}

Меня уже прождали несколько ночей.

В выбранном отрывке мы рассматриваем ещё одну новую онтологическую метафору “几个黄昏” (несколько ночей). В русском и китайском языковых сознаниях временные метафоры могут объектироваться в конкретных предметах, а также и в ряде их признаков, в том числе и "количество предметов - несколько (几个)". Таким образом, переводчик легко может подобрать эквивалент в целевом языке.

\section{【寄生草】花把青春卖，花生锦绣灾。(《冥判》) Цветы - изменницы нам продают весну, Их краски яркие грозят бедою.}

В данном примере метафорой является "把青春卖" (продают весну). Метафора основа на ассоциации с тем, что весна, как и деньги или другие ценные вещи, может быть продана (卖). Русские и китайские народы для характеристики времени употребляют одинаковое слово: "продавать" (卖), поэтому переводчик передаёт оригинал напрямую, через эквивалентную метафору, существующую в русской культуре.

【山桃红】则为你如花美眷，似永流年，是答儿闲寻 遍。在幽闺自怜。(《惊梦》)

Ведь ради вас, прекрасной, как цветок,

Я обошёл селения и города,

И вас нашёл в укромном терему,

В тоске о юнㅜㅜㄲํ, текущей, как вода.

В оригинальном тексте можно найти метафорическое выражение: “似水流年” (юность, текущая, как вода). Данная метафора является структурной. В русском языке также существуют подобные выражение: "время течёт, как вода". Кроме того, в сознаниях русского и китайского народов время может не только "течь", но и "останавли- 
ваться", "замерзать" и т.д. Таким образом, метафорический образ исходного текста полностью был сохранен переводчиком в целевом тексте.

Как мы видим в предыдущих примерах, полный перевод основывается на сходствах между русскими и китайскими языковыми временными метафорами. На самом деле, иногда полный перевод употребляется и в той ситуации, когда в русском языке вообще не существует подобного метафорического образа, как в китайском. К примеру:

\section{【啭林莺】当今生花开一红，愿来生把萱椿再奉。 《闹姃》) \\ Цвет юности моей поникнул и увял, \\ Но в жизни будущей я долг верну сполна.}

В данном примере есть две специфические метафоры в оригинале: “今生” (настоящая жизнь) и “来生” (будущая жизнь или следующая жизнь), они вместе с "前生" (прежняя жизнь) создают концепцию жизни и смерти в буддизме. Существенное влияние буддизм оказал на носителей китайской культуры, и конечно, на творчество китайской литературы. В опере “Пионовая беседка" как раз говорится о том, что произошло в настоящей и в будущей жизни у Ду Линьян. Вся история, описанная в оригинальном тексте, конструируется и основывается на возможности того, что человек после смерти может выходить из своего тела, пребывать в промежуточном состоянии, то есть в состоянии между смертью и новым рождением, а потом переходить из одной жизни в другую, так называемую следующую жизнь. Таким образом, сансара (轮回) является одним из основных понятий в буддизме. Большинство россиян являются христианами, так что русский народ не ассоциирует время с таким понятием, которое движется по бесконечному циклу повторяющихся рождений, земного существования и смерти. Такое циклическое движение времени для русских читателей может быть чуждым. Несмотря на это, переводчик сохранил метафорическое выражение исходного текста при переводе: первую переводчик передаёт как " юность моя" , а вторую как "жизнь будущая", что сохранило культурные особенности, поспособствовало внешнему распространению и влиянию национальной культуры и ценностей в культуре русского языка, помогло русским читателям понять смысл всего текста на более глубоком уровне.

\section{(2) Трансформашионный перево}

Следующим способом, который также часто используется переводчиком “Пионовой беседки", является трансформационный перевод. Он применяется в том случае, если появляется ассоциативное несоответствие между метафорами в исходном и целевом языках. Переводчик заменяет исходную метафору другим метафорическим образом, присутствующим в целевом языке, при- меняет определённые преобразования с целью более доступной передачи информации, объяснения исходного смысла метафоры русским читателям с отличной от китайской культурой.

\section{【前腔】阳春有脚，经过百姓人家。(《劝农》)}

Вы, как солнышко весною;

Заглянули в каждый дом.

В этом примере мы можем видеть, что переводчик заменил выражение 《阳春经过百姓人家》 (Весна прогуливается по домам жителей) в исходном тексте выражением «весна, заглянула в каждый дом». Данная трансформация не наносит ущерба эффекту метафорического образа оригинального текста, а наоборот, помогает минимизировать культурную разницу между двумя языками, делает переведенный текст более аутентичным и легким для понимания. Текст перевода, в той же степени, что и оригинальный текст, может передать радостное и возбуждённое настроение людей по весне.

\section{(3) Вольный перевоА}

Вольный перевод относится к ситуации, когда переводчик преобразует метафорическое выражение в тексте оригинала, используя неметафорическое выражение в целевом языке. Приведём пример:

\section{【皇罗袍】锦屏人忒看的这韶光贱! (《惊梦》) \\ Как чудно видеть нам, затворницам, всю эту прелесть!}

В предложенном примере мы можем найти такую метафору: “韶光贱” (тратить прекрасная пора весны зря). Архаизм “贱” тут обозначает “недооценивать, пренебрегать, относиться несерьёзно, тратить зря". Прекрасная весенняя пора (韶光), как одно абстрактное понятие, может ассоциироваться с таким конкретным осязаемым предметом, как "деньги", которые могут быть потрачены зря. Хотя в русском языке также существует подобная метафора, переводчик вместо сохранения метафорического образа оригинального текста решил передать смысл, закладываемый автором, через неметафорическое выражение. Однако переведённый текст, по нашему мнению, не сможет полностью отражать психологическое состояние Ду Линян: она на самом деле не только восхваляет красоту весны, но и самое главное, страдает от феодальной идеологии, от того, что она, как незамужняя девушка, не сможет выйти из дома, наслаждаться весной на улицах или встретиться со своим любимым. В тексте перевода это отражено не было.

\section{(4) Приём опушения}

Ещё одним частотным случаем при переводе вре- 
менных метафор является приём опущения. Приём опущения - переводческий приём, характеризующийся пропуском в целевом языке единиц, которые присутствуют в тексте исходного языка, при сохранении семантической эквивалентности. Данный приём перевода часто используется для устранения избыточности. Например:

\section{【前腔】殿策贤良，榜下诸生候久长。（《榜下》）}

Студенты все экзамены прошли,

Давно уж оглашения итогов ждут.

В приведенном примере существуют две онтологические метафоры: “время ожидания давнее" (候久) и "время ожидания длинное" (候长). В переводе опущена лексическая единица “长” (длинно) . В сочетании с"ждать"данное определение ("давно") приводит к тавтологии в русском переводе, поскольку значение наречия “давно" уже содержит в себе указание на время.

\section{Зак^ючение}

Из вышеприведённых примеров наглядно видно, что метафора времени является одной из самых важных и сложных лингвистических проблем с точки зрения её перевода, так как между русскими и китайскими временными метафорами существуют не только сходства, но и различия. Очень важно для переводчика проводить сопоставительное изучение временной метафоры в исходном и целевом языках, учитывать характерные особенности в представлении понятия времени и специфические метафорические модели в обеих культурах. На основе проведённого исследования возможно выделить всего четыре наиболее подходящих способа для передачи временных метафор: полный перевод, трансформационный перевод, вольный перевод и приём опущения. С помощью вышеупомянутых способов переводчик сможет достичь максимальной эквивалентности между текстом оригинала и перевода в своей работе, а также обеспечения эстетического эффекта.

\section{ЛИТЕРАТУРА}

1. Арутюнова Н.Д. Язык и мир человека. - М.: Языки русской культуры, 1998. - С. 366.

2. Бархударов Л.С. Язык и перевод. Вопросы общей и частной теории перевода. / Л.С. Бархударов. - М.: Международные отношения, 1975. -324с.

3. Блэк М. Метафора // Теория метафоры / Отв. ред. Н.Д. Арутюнова. - М.: Изд-во «Прогресс», 1990. - С. 156.

4. Будаев Э.В. Становление когнитивной теории метафоры // Лингвокульторология. - 2007. - №1. - С. 19.

5. Дэвидсон Д. Что означают метафоры // Теория метафоры / Отв. ред. Н.Д. Арутюнова. - М.: Изд-во «Прогресс», 1990. -

6. Лакофф Дж. Джонсон М. Метафоры, которыми мы живем. - М.: Изд-во ЛКИ, 1990. - С. 23. С.174.

7. Никитин М.В. Концепт и метафора // Проблема теории европейских языков / Отв. ред. В.М. Аринштейн, Н.А. Абиева, Л.Б. Копчук. - СПб: Изд-во «Тригон», 2001. - C.36.

8. Казакова Т.А. Теория перевода (лингвистические аспекты)/Т.А. Казакова. - СПБ.: Союз, 2003. -296.с.

9. Комиссаров В.Н. Современное переводоведение. /В.Н. Комиссаров - М.: Изд-во “ЭТС", 2000.-424С.

10. Carlstein T. Introduction // Timing Space and Spacing Time. V.I. Making Sense of Time / Eds. Carlstein, Parkes, Thrift. Edward Arnold: London, 1978. PP. 1-7.

11. 汤显祖著，李英男译，牡丹亭 (Пионовая беседка) [M].湖南：湖南人民出版社， 2016.

(c) СюйЧан (zlama@foxmail.com). 